\title{
Hospital Workforce Engagement and Inpatient Mortality Rate: Findings from the English National Health Service Staff Surveys
}

\author{
R. G. Badgett, $M D^{7}$ (1) L. Jonker, $P h D^{2}$, and S. Xirasagar, MBBS, PhD ${ }^{3}$
}

'Department of Internal Medicine, University of Kansas School of Medicine-Wichita, Wichita, KS, USA; ${ }^{2}$ Research \& Development Department, North Cumbria Integrated Care NHS Foundation Trust, Carlisle, UK; ${ }^{3}$ Department of Health Services Policy and Management, Arnold School of Public Health, University of South Carolina, Columbia, SC, USA.

BACKGROUND: Healthcare workforce engagement may represent a proactive approach against provider burnout, a widely prevalent condition that is associated with poor patient outcomes.

OBJECTIVE: We examine whether workforce engagement is associated with better hospital performance, measured as lower inpatient mortality, in English National Health Services (NHS) acute Trusts.

DESIGN: Panel study using cross-lagged regression, applying an optimally time-lagged value of the dependent variable as covariate to account for unmeasured Trust characteristics.

PARTICIPANTS: NHS acute Trusts and respondents to the NHS Staff Surveys, 2012-2018.

MAIN MEASURES: We measured engagement using three survey questions corresponding to validated engagement factors, and hospital performance using the Summary Hospital-level Mortality Indicator (SHMI). In the first analyses, associations of SHMI (dependent variable) with workforce engagement in the current, prior, and subsequent years were studied to find the optimum lag period for lagged regression analysis. In the subsequent cross-lagged regression analysis, bi-directional associations between SHMI and engagement were studied. Heterogeneity in engagement components across Trusts was studied in detail for the year 2017.

KEY RESULTS: In the first analyses, current SHMI was negatively associated with engagement in the current year $(\beta=-0.044 ; p=0.035)$ more than with the prior year $(\beta=-0.037 ; p=0.049)$. In the second analysis, (a) engagement predicted same-year SHMI after controlling for prior-year SHMI $(\beta=-0.044 ; p=0.035)$. A 1-unit higher engagement score was associated with 4.4\% lower SHMI. (b) SHMI predicted engagement in the same year $(\beta=-0.066 ; p=0.001)$ after controlling for prior-year engagement. More in-depth analysis showed high inter-trust heterogeneity on all three engagement factors $\left(I^{2}>85 \%\right)$.

CONCLUSION: Higher workforce engagement predicts lower mortality which in turn predicts engagement.

Electronic supplementary material The online version of this article (https://doi.org/10.1007/s11606-020-06045-0) contains supplementary material, which is available to authorized users.

Received November 8, 2019

Accepted July 7, 2020

Published online October 13, 2020
Heterogeneity in workforce well-being suggests an opportunity to foster mutual learning across Trusts.

$\mathrm{J}$ Gen Intern Med 35(12):3465-70

DOI: $10.1007 / \mathrm{s} 11606-020-06045-0$

(c) Society of General Internal Medicine 2020

\section{BACKGROUND}

Healthcare management research has focused on burnout as nearly half of physicians and one-third of the US working population report burnout. ${ }^{1}$ Similarly, about $40 \%$ of consultants in the National Health Service (NHS) report burnout. ${ }^{2}$ Burnout also affects the worker's role performance and may reduce organizational performance. ${ }^{3}$ Research focusing on positive workforce states may be useful to facilitate better outcomes for both provider well-being and organizational outcomes. Aspirational goals to improve workforce morale could be (1) engagement, a validated construct defined as "a positive fulfilling, work-related state of mind characterized by vigor, dedication, and absorption,"4 and (2) thriving, which is a combination of engagement and a drive for learning or selfimprovement. These higher states are associated with extrarole performance and prosocial actions, 5,6 reduced burnout, and improved employee and organizational performance in business organizations. $4,7,8$ There are no data sources that capture healthcare workforce measures of thriving; however, engagement is measured annually in the English Trusts of the National Health Service (NHS). This study examines whether workforce engagement in the NHS is associated with lower inpatient mortality.

\section{METHODS}

We executed a panel study using the annual NHS Staff Surveys from 2012 to 2018 . We limited the study to the Trusts of the English NHS because availability of the adjusted mortality indicator is limited to English hospitals, the organizational outcome of interest. Due to prior findings that engagement varies by Trust type and survey respondents' profession, ${ }^{9}$ we limited our study to acute, non-specialty Trusts. Acute Trusts are organizations within the English NHS that include one or 
more hospitals providing secondary health services with financial and managerial autonomy to improve organizational performance and care quality. The survey was administered by each Trust using national guidance from the NHS. Through the year 2015, the NHS required all staff to be surveyed unless a Trust had more than 600 staff in which case a random sample of staff beyond 600 were sampled (Table 1). Since 2016, the threshold for allowing a supplemental random sample was a staff size of 1250 .

The NHS Staff Survey considers engagement to have three dimensions: psychological motivation, involvement in the organization, and advocacy for the organization. ${ }^{10} \mathrm{We}$ used Schaufeli's more widely used and validated definition of engagement which captures only the motivation dimension. ${ }^{4}$ In this view, advocacy and involvement are considered outcomes rather than components of engagement. ${ }^{5,6}$ In the Staff Surveys, engagement was measured by Likert scale responses (1 never to 5 always) to three questions representing dedication ("I am enthusiastic about my job"), absorption ("time passes quickly when I am working"), and vigor ("I look forward to going to work") adapted from Schaufeli's validated UWES-9 survey. ${ }^{4}$ Individual mean scores across all three questions were aggregated into a Trust level workforce "engagement score." The Summary Hospital-level Mortality Indicator (SHMI) data were obtained from NHS Digital. ${ }^{11}$ Each Trust's SHMI is the ratio of observed deaths during hospitalization to expected number of deaths based on the average mortality rate for English hospitals adjusted for the Trust's case-mix.

Our goal was to study whether same-year engagement predicts SHMI and, in turn, whether SHMI predicts engagement. ${ }^{12}$ The associations between engagement and mortality were assessed in a two-step process. As shown in Figure 1, we first identified the optimal lag between workforce engagement and mortality by studying SHMI prediction by the Trust-level engagement score in the same year and prior years (analysis 1). Using the optimal lag, we used cross-lagged regression, a technique to adjust for baseline mortality of the Trust by including the optimum lag SHMI as an independent variable in the model when assessing the net association of engagement with the mortality outcome (analysis 2). The associations tested are shown in Figure 2. Crossed-lagged regression allows estimation of the "unique effects of job attitudes on later performance (with baseline performance controlled) and of performance on later job attitudes (with baseline job attitudes controlled)." 12 Thus, crossed-lagged regression, by controlling for the baseline status of the dependent variable, accounts for measured and unmeasured Trust characteristics that may confound the association of interest.

We weighted all regression analyses by the number of respondents at each Trust who reported having frequent contact with patients, assuming frequent patient contact to be a proxy for caregiver staff. The appendix tables (Tables 4 and 5) display the results of alternate approaches to weighting that were considered but not used. We used the number rather than the proportion of clinical respondents as using the proportion would ignore Trust size. The additional contribution of each independent variable in predicting the dependent variable beyond the effect of the other variables in the regression was assessed by dominance analysis. ${ }^{13}$ Each variable's contribution to total variance is designated $R^{2}$

We studied 2017 engagement data in depth, using each factor of engagement separately, to assess the role of heterogeneity in workforce engagement components across Trusts in predicting mortality. We used random effects analyses with the HartungKnapp estimator, ${ }^{14}$ with responses dichotomized by always/often versus other. Heterogeneity in the rates of engagement across Trusts was measured with the $I^{2}$ statistic. The $I^{2}$ statistic is the proportion of total variation across Trusts that is due to heterogeneity between Trusts. ${ }^{15}$ The $I^{2}$ value is interpreted as follows: " 0 to $40 \%$ : may not be important; 30 to $60 \%$ : moderate heterogeneity; 50 to $90 \%$ : substantial heterogeneity; 75 to $100 \%$ : considerable heterogeneity." 15 All statistical analyses were performed with the R Programming Language ${ }^{16}$ version 3.6.2 using the procedure programs for dominance analysis ${ }^{17}$ and meta. ${ }^{18}$

Table 1 Characteristics of Surveyed Populations in the English, Acute Trusts

\begin{tabular}{|c|c|c|c|c|c|c|c|}
\hline & $\begin{array}{l}\text { Number of } \\
\text { Trusts with } \\
\text { public data }\end{array}$ & $\begin{array}{l}\text { Number of } \\
\text { Trusts with } \\
\text { public } \\
\text { engagement } \\
\text { data }\end{array}$ & $\begin{array}{l}\text { Trust staff size up } \\
\text { to which full } \\
\text { census } \\
\text { participation } \\
\text { required* }\end{array}$ & $\begin{array}{l}\begin{array}{l}\text { Surveys } \\
\text { distributed }^{\dagger}\end{array} \\
\end{array}$ & $\begin{array}{l}\text { Response rate } \\
\text { (range across } \\
\text { Trusts) }\end{array}$ & $\begin{array}{l}\text { Proportion } \\
\text { reporting } \\
\text { frequent patient } \\
\text { contact (range } \\
\text { across trusts) }\end{array}$ & $\begin{array}{l}\text { Mean } \\
\text { engagement } \\
\text { score }^{\text {S }} \text { (standard } \\
\text { deviation) }\end{array}$ \\
\hline 2012 & 142 & 142 & 600 & 116,455 & $49 \%$ ( 27 to $71 \%$ ) & $71 \%$ (64 to $85 \%$ ) & $3.83(0.086)$ \\
\hline 2013 & 141 & 140 & 600 & 249,592 & $49 \%$ (30 to $78 \%$ ) & $71 \%$ (61 to $80 \%)$ & $3.86(0.081$ \\
\hline 2014 & 138 & 136 & 600 & 378,437 & $42 \%$ ( 23 to $82 \%)$ & $70 \%(62$ to $80 \%)$ & $3.85(0.093)$ \\
\hline 2015 & 137 & 134 & 600 & 469,219 & $41 \%$ ( 25 to $78 \%)$ & $68 \%$ (57 to $80 \%)$ & $3.94(0.075)$ \\
\hline 2016 & 138 & 134 & 1250 & 643,320 & $43 \%$ (29 to $77 \%)$ & $68 \%(59$ to $80 \%)$ & $3.94(0.066)$ \\
\hline 2017 & 136 & 132 & 1250 & 748,678 & $43 \%(27$ to $73 \%)$ & $67 \%(60$ to $78 \%)$ & $3.92(0.085)$ \\
\hline 2018 & 132 & 130 & 1250 & 755,206 & $43 \%(25$ to $72 \%)$ & $68 \%(58$ to $78 \%)$ & $3.93(0.064)$ \\
\hline
\end{tabular}

*If Trust staff size was less than the maximum size, a census was required. If the staff size was more than the maximum size, additional random sampling was allowed. Since 2016, the NHS has encouraged surveying all staff. This information was gathered from each year's technical or guidance document at https://www.nhsstaffsurveys.com/

${ }^{\dagger}$ This information was gathered from each year's technical or guidance document at https://www.nhsstaffsurveys.com/

${ }^{7}$ Response rates gathered from the yearly Staff Surveys themes or key findings reports from https://www.nhsstaffsurveys.com/

${ }^{\xi}$ For engagement score: $5=$ always; $4=$ often; $3=$ sometimes; $2=$ rarely; $1=$ never 


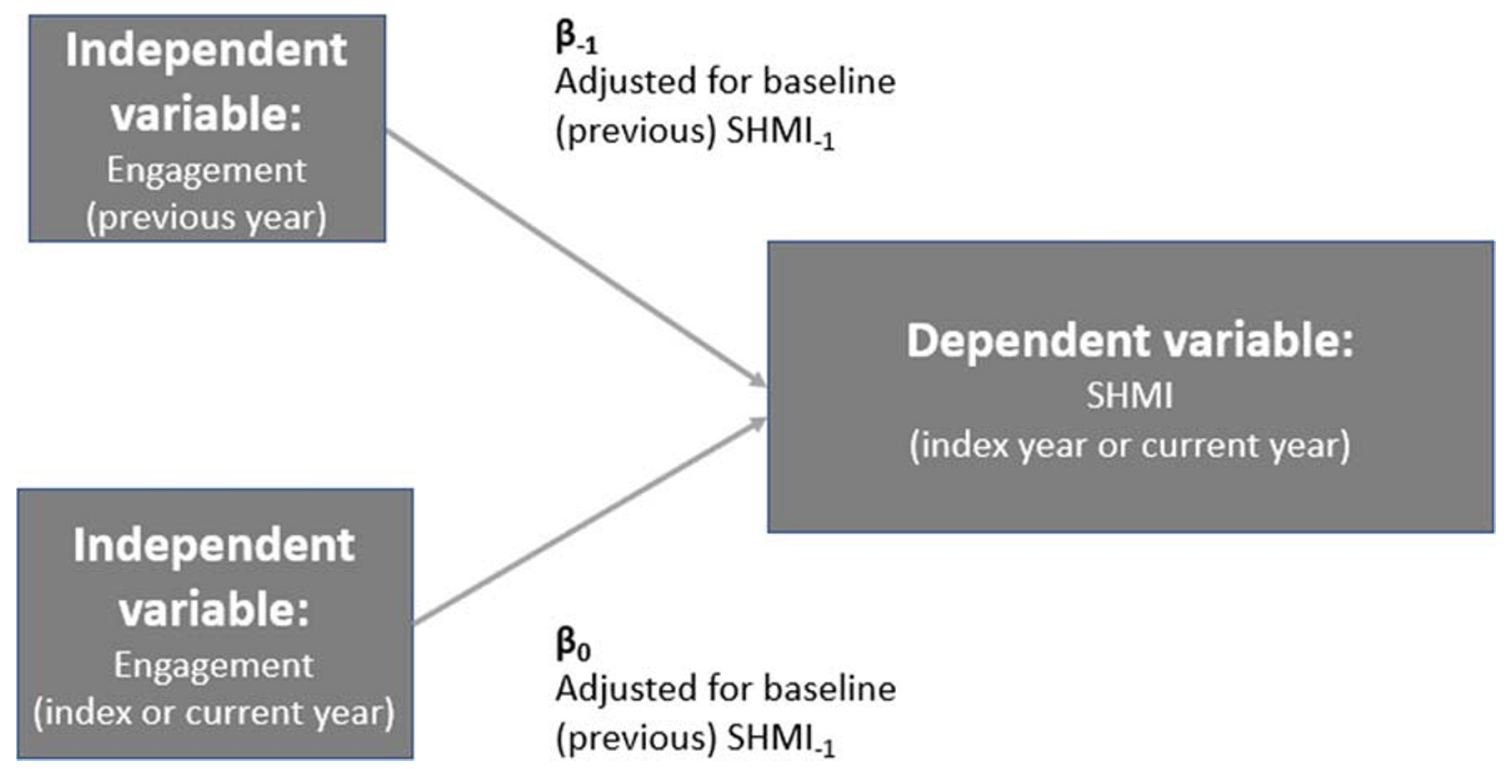

Fig. 1 Analysis 1: Determining the length of the optimal lag between engagement and SHMI.

\section{RESULTS}

The number of Trusts participating in the survey with data on workforce engagement varied between 142 in 2012 and 132 in 2018. Average number of staff respondents per Trust varied from 404 in 2012 to 5721 in 2018 (Table 1). However, engagement data are available for fewer than the total number of participating Trusts because not all Trusts asked engagement questions every year (Table 1). The average staff response rate across all Trusts was 43\% (range: $41 \%$ in 2015 to
$49 \%$ in 2013). The proportion of staff per Trust reporting frequent contact with patients varied between 68 and $71 \%$. Pooling data for all years with engagement data available, Trust SHMI ranged between 0.9996 and 1.0044, a variation range of -0.04 and $+0.44 \%$ relative to expected mortality. The median SHMI was similar across study years. The mean engagement score across Trusts (all-staff types included) ranged between 3.83 and 3.94, with no significant differences in median engagement scores by year.

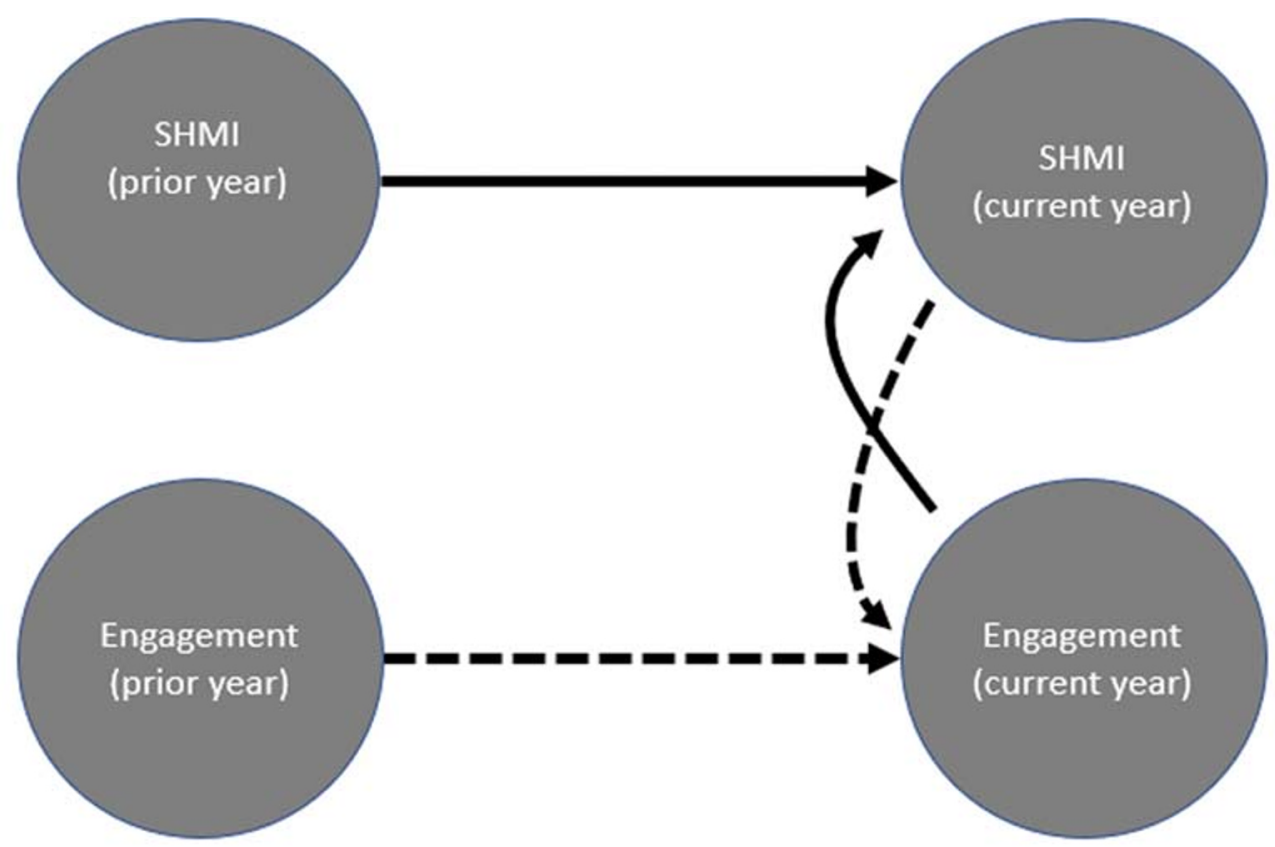

Measuring the impact of engagement on SHMI, controlling for prior SHMI.

- Measuring the impact of SHMI on engagement, controlling for prior engagement.

Fig. 2 Analysis 2: Lagged regression based on the results of analysis 1. 
In analysis 1, using the 2013-2017 pooled data, SHMI in a given year was negatively associated with engagement in the same year $(\beta=-0.044 ; p=0.035)$; i.e., each unit difference in engagement score was associated with a 4.4\% lower SHMI in the same year. Same-year association was greater than the association in the prior year, though the latter was borderline statistically significant (Table 2). Thus, a short lag of 1 year was deemed optimal to use in the second analysis (to control for unmeasured Trust-level effects on SHMI). In analysis 2, using the short lag, workforce engagement predicted same-year SHMI after controlling for prior-year SHMI $(\beta=-0.043$; $p=0.035$ ); i.e., after adjusting for prior-year SHMI, a 1unit higher engagement score (for a simplistic example, if a Trust moved all of its responses from "sometimes" to "often") was associated with $4.3 \%$ lower SHMI in the same year. Further, a reverse association was detected: SHMI predicted engagement in the same year $(\beta=-$ $0.066 ; p=0.001)$ after controlling for prior-year engagement (Table 3). The reverse association persisted: indexyear SHMI predicted engagement in the ensuing year $(\beta=$ $-0.186 ; p<0.001)$.

Dominance analysis showed that engagement in the same year accounted for an additional $1 \%$ of SHMI variability after adjusting for prior-year SHMI (Table $3 ; R_{\Delta}^{2}=0.011$ ). Engagement in a given year accounted for $43 \%$ of the variation in engagement in the ensuing year (data not shown).

In a detailed, univariate analysis of the 2017 data, the proportions of all-staff respondents at each Trust who responded often/always to the three engagement questions were dedication $74 \%$ (range 67 to $80 \%$ ), absorption $77 \%$ (72 to $84 \%$ ), and vigor $58 \%$ (50 to $67 \%$ ) with the $I^{2}$ statistic indicating considerable ${ }^{19}$ inter-Trust heterogeneity on all three questions $\left(I^{2}>80 \%\right) .{ }^{19}$ The correspondence of engagement with SHMI is presented in Figure 3 showing the percentage of respondents reporting always feeling dedicated and the corresponding Trust SHMI in Trusts with the 5 highest and 5 lowest scores on all-staff dedication, a component of engagement.

Table 2 Regression Analyses Results Showing Associations of Workforce Engagement, in the Previous and Current Years, with Current SHMI Pooled Across the Years 2013-2018 $(n=683$ TrustYears from 143 Trusts)

\begin{tabular}{lll}
\hline \hline & $\begin{array}{l}\text { Previous-year } \\
\text { engagement ("long } \\
\text { lag") }\end{array}$ & $\begin{array}{l}\text { Same-year } \\
\text { engagement } \\
\text { ("short lag") }\end{array}$ \\
\hline$B$ estimate & -0.037 & -0.044 \\
Significance $(p)$ & 0.049 & 0.035 \\
$R^{2}$ (proportion of SMHI & 0.792 & 0.791 \\
variation explained by & & \\
model)* & & \\
\hline
\end{tabular}

SHMI Summary Hospital-level Mortality Indicator

Models include the previous year's SMHI to adjust unmeasured confounders and are weighted by the number of clinical respondents in each Trust

$* R^{2}$ is adjusted for the number of predictors in the model
Table 3 Cross-Lagged Regression Analyses Showing SHMI Predicting Current Engagement Adjusted for Prior-Year Engagement and Current Engagement Predicting Current SHMI Adjusted for Prior-Year SHMI, 2013-2018

\begin{tabular}{ll}
\hline \hline $\begin{array}{l}\text { SHMI in the current year } \\
\text { predicted by current } \\
\text { engagement (covariate previous } \\
\text { SHMI) }\end{array}$ & $\begin{array}{l}\text { Engagement in the current year } \\
\text { predicted by current SHMI } \\
\text { (covariate previous engagement) }\end{array}$ \\
\hline-0.044 & -0.066 \\
$p=0.035$ & $p=0.001$ \\
$R_{\Delta}^{2}=0.011 *$ & $R_{\Delta}^{2}=0.011 *$ \\
\hline
\end{tabular}

SHMI Summary Hospital-level Mortality Indicator

Models are weighted by the number of clinical respondents in each Trust

$* R_{\Delta}^{2}$ is the change in the $R^{2}$ due to the independent variable alone

\section{DISCUSSION}

Our finding that healthcare workforce engagement is associated with lower mortality is consistent with previously documented findings in business settings showing an association between engagement and organizational performance. ${ }^{6,8,12}$ This association was reported in an in-house, NHS organizational report using 2 years of NHS data. ${ }^{9}$ Our study using data across 7 years shows that this association is stable across multiple years as we had the ability to treat each year's data on a Trust as a unique observation, and therefore changes in engagement, positive or negative, contributed to the observed associations in our study. Our adjustment for prior-year SHMI mitigates the association-inflating effect of treating repeated measures as unique, independent observations in pooled data analysis. A new finding of our study is the reverse association that current SHMI predicts current engagement after adjusting for prior engagement. Another new finding is that of "considerable" heterogeneity in staff engagement across Trusts $\left(I^{2}>\right.$ $80 \%)$.

The engagement effect in the NHS appears to be similar to its effect on business measures of organizational performance that is documented in the business literature. First, the lag period for which engagement continues to impact performance is short, documented to be less than a year. ${ }^{12}$ Second, engagement levels appear to be durable over time. Our dominance analysis found that $43 \%$ of variance in engagement in the ensuing year is explained by the engagement in the current year. This supports Schaufeli's finding that 31 to $53 \%$ of engagement in a second measurement is explained by the first measurement. The less than $100 \%$ persistence of engagement levels suggests that organizational leaders and culture may affect engagement. ${ }^{4}$

The reciprocal directions of association that engagement affects mortality and vice versa suggests that organizations can create a virtuous positive cycle. This cycle may represent a Matthew effect. ${ }^{20}, 21$ The Matthew effect describes preferential attachment and cumulative advantage in which success breeds success, and advantage tends to beget further advantage. ${ }^{20}$ This may contribute to the considerable heterogeneity of engagement that we found across Trusts. Whether this is 


\section{Trust*}

RHM

RAP

RBA

RRF

RD3
SHMI†

\section{Trusts with highest dedication}

Proportion

$95 \%-\mathrm{Cl}$
$0.78[0.77 ; 0.79]$
$0.78[0.76 ; 0.80]$
$0.78[0.76 ; 0.80]$
$0.79[0.75 ; 0.83]$
$0.80[0.78 ; 0.82]$

0.86

0.89

1.17

0.86

\section{Trusts with lowest dedication}

RE9
RXH
RM3
RJL
RQ6
Random effects model
Heterogeneity: $I^{2}=85 \%$

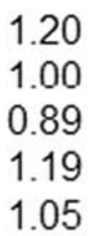

1.00

0.89

1.19

1.05

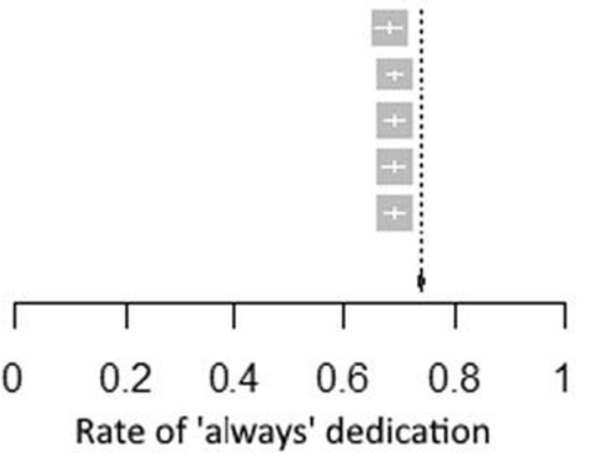

$0.68[0.66 ; 0.70]$

$0.69[0.68 ; 0.70]$

$0.69[0.67 ; 0.71]$

$0.69[0.67 ; 0.71]$

$0.69[0.67 ; 0.71]$

\section{Notes: \\ * Trust organisational code † Summary Hospital-level Mortality Indicator}

Fig. 3 Five NHS Trusts with respective highest and lowest reported rates for the dedication component of engagement.

mediated by active human resource policies to increase employee engagement through soliciting employee participation, decentralized decision-making, and team-building as postulated in the literature should be explored in future studies in order to identify organizational approaches that are effective in increasing workforce engagement. ${ }^{7}$

The observed heterogeneity in workforce engagement across Trusts suggests opportunities to foster mutual learning and sharing of organizational development strategies between Trusts with high engagement and those with lower than average engagement levels. Rose has documented successful efforts at created learning and improvement across units of a dispersed organization using positive deviance. ${ }^{22,} 23$

Our findings for engagement agree with prior findings reported for burnout. In a recent review of burnout and the quality of care, ${ }^{3}$ two studies of emotional exhaustion and adjusted mortality in over 50 clinical sites found a similar proportion of inter-site variation in mortality being explained by emotional exhaustion, ${ }^{24}{ }^{25}$

Our study has some limitations. First, we had access to aggregated data at the level of the Trusts rather than responses of individual staff or staff categories. We did not assess other organizational factors that have been studied or postulated to affect organizational performance such as mortality. These factors include high-performance human resource management (HRM) ${ }^{7}$ research activity, ${ }^{26}$ openness, ${ }^{27}$ and a Freedom to Speak Up Index. ${ }^{28}$ As HRM is considered an antecedent to engagement and extra-role behavior is considered an expected outcome of employee well-being, ${ }^{5,6}$ we did not include them in our assessment of engagement. However, the additional impact of these factors merits future research. Additional factors, currently not captured in the Staff Survey, merit inclusion in future surveys. These factors include thriving ${ }^{5}$ and calling. ${ }^{29}$ As thriving (ongoing workforce learning and improvement combined with engagement) and calling (defined as "work that a person perceives as his purpose in life" ${ }^{29}$ ) may better predict organizational performance, addition of validated measures of the learning dimension to the NHS surveys may improve the utility of survey findings for improving Trust performance. $^{30-32}$

Our second limitation is the lack of availability of shorter lags to study. The strongest lag between work attitude and job performance may be less than a year. ${ }^{12,33}$ This is consistent with our finding that engagement and SHMI affect each other the most when measured during the same year. Presumably, as the year progresses, the impact of engagement and SHMI starts impacting each other before the year is complete. The NHS might survey their staff every 6 months as done by Google. $^{34}$

In conclusion, our findings indicate that staff engagement is important to maximize patient outcomes, particularly inhospital mortality. Heterogeneity in workforce engagement across Trusts suggests an opportunity for improvement, 
specifically through mutual sharing of recipes for success and learning between Trusts. With increasing roles of hospitalists in the care management of inpatients in the USA and internationally, our findings present opportunities for hospital and multi-hospital system leaders to initiate human resource initiatives to improve healthcare workforce well-being, prevent and combat burnout, and improve patient outcomes.

Data Availability: Data files and analytic code are available at https://ebmgt.github.io/.

Corresponding Author: R. G. Badgett, MD; Department of Internal Medicine, University of Kansas School of Medicine-Wichita, Wichita, KS, USA (e-mail: rbadgett@kumc.edu).

\section{Compliance with Ethical Standards:}

Conflict of Interest: The authors declare that they do not have a conflict of interest.

\section{REFERENCES}

1. Shanafelt TD, West CP, Sinsky C, et al. Changes in burnout and satisfaction with work-life integration in physicians and the general US working population between 2011 and 2017. Mayo Clin Proc. 2019. https://doi.org/10.1016/j.mayocp.2018.10.023

2. Khan A, Teoh KR, Islam S, Hassard J. Psychosocial work characteristics, burnout, psychological morbidity symptoms and early retirement intentions: a cross-sectional study of NHS consultants in the UK. BMJ Open. 2018;8(7):e018720. https://doi.org/10.1136/bmjopen-2017-018720

3. Tawfik DS, Scheid A, Profit J, et al. Evidence relating health care provider burnout and quality of care: a systematic review and meta-analysis. Ann Intern Med. 2019. https://doi.org/10.7326/M19-1152

4. Schaufeli WB. The measurement of work engagement with a short questionnaire: a cross-national study. Educ Psychol Meas. 2006;66(4):701-716. https://doi.org/10.1177/0013164405282471

5. Spreitzer GM, Porath CM. Self-Determination as a Nutriment for Thriving: Building an Integrative Model of Human Growth at Work Page. In: Gagne M, ed. The Oxford Handbook of Work Engagement, Motivation, and Self-Determination Theory. 1st Oxford Library of Psychology, Oxford ; New York: Oxford University Press; 2014:245-258.

6. Seibert SE, Wang G, Courtright SH. Antecedents and consequences of psychological and team empowerment in organizations: a meta-analytic review. J Appl Psychol. 2011;96(5):981-1003. https://doi.org/10.1037/ a0022676

7. West MA, Guthrie JP, Dawson JF, Borrill CS, Carter M. Reducing patient mortality in hospitals: the role of human resource management. J Organ Behav. 2006;27(7):983-1002. https://doi.org/10.1002/job.396

8. Bailey C, Madden A, Alfes K, et al. Evaluating the evidence on employee engagement and its potential benefits to NHS staff: a narrative synthesis of the literature. Health Serv Deliv Res. 2015;3(26). https://doi.org/10. $3310 /$ hsdr03260

9. West MA, Dawson JF. Employee Engagement and NHS Performance. The King's Fund: The King's Fund; 2012:23. https://www.kingsfund.org.uk/ sites/default/files/employee-engagement-nhs-performance-west-dawson-leadership-review2012-paper.pdf. Accessed February 2, 2020.

10. Fletcher L, Robinson D, Truss C, et al. Measuring Employee Engagement and Interpreting Survey Results | Institute for Employment Studies (IES). 2014. http://www.employment-studies.co.uk/resource/measuring-employee-engagement-and-interpreting-survey-results. Accessed February 2,2020

11. United Kingdom National Health Service. Summary Hospital-level Mortality Indicator (SHMI) - Deaths associated with hospitalisation. NHS Digital. https://digital.nhs.uk/data-and-information/publications/clinical-indicators/shmi. Accessed September 22, 2019.

12. Riketta M. The causal relation between job attitudes and performance: a meta-analysis of panel studies. J Appl Psychol. 2008;93(2):472-481. https://doi.org/10.1037/0021-9010.93.2.472
13. Azen R, Budescu DV. The dominance analysis approach for comparing predictors in multiple regression. Psychol Methods. 2003;8(2):129-148. https://doi.org/10.1037/1082-989X.8.2.129

14. Cornell JE, Mulrow CD, Localio R, et al. Random-effects meta-analysis of inconsistent effects: a time for change. Ann Intern Med. 2014;160(4):267270. https://doi.org/10.7326/M13-2886

15. Deeks JJ, HIggins JP, Altman DG. Identifying and measuring heterogeneity. Cochrane Handbook for Systematic Reviews of Interventions. http://handbook-5-1.cochrane.org/chapter_9/9_5_2_identifying_and_ measuring_heterogeneity.htm. Published March 2011. Accessed February $16,2020$.

16. R Core Team. R: A Language and Environment for Statistical Computing. Vienna, Austria: R Foundation for Statistical Computing; 2019. https:// www.R-project.org/. Accessed February 2, 2020.

17. Navarrete CB. Package "Dominance analysis."; 2020. https://cran.rproject.org/web/packages/dominanceanalysis/.

18. Schwarzer G. Package "Meta."; 2020. https://cran.r-project.org/web/ packages/meta/.

19. Higgins JPT, Thompson SG, Deeks JJ, Altman DG. Measuring inconsistency in meta-analyses. BMJ. 2003;327(7414):557-560. https://doi.org/ $10.1136 / \mathrm{bmj} .327 .7414 .557$

20. Perc M. The Matthew effect in empirical data. J R Soc Interface. 2014;11(98):20140378. https://doi.org/10.1098/rsif.2014.0378

21. Rigney D. The Matthew Effect: How Advantage Begets Further Advantage. First Edition edition. New York: Columbia University Press; 2010.

22. Rose AJ, McCullough MB. A practical guide to using the positive deviance method in health services research. Health Serv Res. 2017;52(3):12071222. https://doi.org/10.1111/1475-6773.12524

23. Rose AJ, Petrakis BA, Callahan P, et al. Organizational characteristics of high- and low-performing anticoagulation clinics in the Veterans Health Administration. Health Serv Res. 2012;47(4):1541-1560. https://doi. org/10.1111/j.1475-6773.2011.01377.x

24. Welp A, Meier LL, Manser T. Emotional exhaustion and workload predict clinician-rated and objective patient safety. Front Psychol. 2014;5:1573. https://doi.org/10.3389/fpsyg.2014.01573

25. Davenport DL, Henderson WG, Mosca CL, Khuri SF, Mentzer RM. Riskadjusted morbidity in teaching hospitals correlates with reported levels of communication and collaboration on surgical teams but not with scale measures of teamwork climate, safety climate, or working conditions. J Am Coll Surg. 2007;205(6):778-784. https://doi.org/10.1016/j.jamcollsurg.2007.07.039

26. Jonker L, Fisher SJ. The correlation between National Health Service trusts' clinical trial activity and both mortality rates and care quality commission ratings: a retrospective cross-sectional study. Public Health. 2018;157:1-6. https://doi.org/10.1016/j.puhe.2017.12.022

27. Toffolutti V, Stuckler D. A culture of openness is associated with lower mortality rates among 137 English National Health Service Acute Trusts. Health Aff Proj Hope. 2019;38(5):844-850. https://doi.org/10.1377/ hlthaff.2018.05303

28. Hughes H. Freedom to speak up - the role of freedom to speak up guardians and the National Guardian's Office in England. Future Healthe J. 2019;6(3):186-189. https://doi.org/10.7861/fhj.2019-0031

29. Chen J, May DR, Schwoerer CE. "Called" to speak up: employees' career calling and voice behavior. Acad Manag Proc. 2016;2016(1):12740. https://doi.org/10.5465/ambpp.2016.12740abstract

30. Leykum LK, Palmer R, Lanham H, et al. Reciprocal learning and chronic care model implementation in primary care: results from a new scale of learning in primary care. BMC Health Serv Res. 2011;11:44. https://doi. org/10.1186/1472-6963-11-44

31. Porath CM, Spreitzer GM, Gibson C, Garnett FG. Thriving at work: toward its measurement, construct validation, and theoretical refinement. J Organ Behav. 2012;33(2):250-275. https://doi.org/10.1002/job. 756

32. Naqshbandi MM, Jasimuddin SM. Knowledge-oriented leadership and open innovation: role of knowledge management capability in Francebased multinationals. Int Bus Rev. 2018. https://doi.org/10.1016/j. ibusrev.2017.12.001

33. Dormann C, Griffin MA. Optimal time lags in panel studies. Psychol Methods. 2015;20(4):489-505. https://doi.org/10.1037/met0000041

34. Bock L. Why everyone hates performance management, and what we decided to do about it. In: Work Rules!: Insights from Inside Google That Will Transform How You Live and Lead. Twelve; 2015: 160.

Publisher's Note: Springer Nature remains neutral with regard to jurisdictional claims in published maps and institutional affiliations. 